\title{
Egocentric Health Networks and Cardiovascular Risk Factors in the ECHORN Cohort Study
}

\author{
Carol R. Oladele, $P h D, M P H^{7}$ (D), Terri-Ann Thompson, $P h D^{7}$, Karen Wang, $M D, M H S^{7}$, \\ Deron Galusha, $\mathrm{MS}^{7}$, Emma Tran, $\mathrm{MPH}^{7}$, Josefa L. Martinez-Brockman, PhD, $M \mathrm{HS}^{\top}$, \\ Oswald P. Adams, DM, MBBS ${ }^{2}$, Rohan G. Maharaj, DM, MBBS 3 , Cruz M. Nazario, PhD4, \\ Maxine Nunez, DPH, MSN $N^{5}$, and Marcella Nunez-Smith, $M D, M H S^{7}$ \\ ${ }^{1}$ Yale University School of Medicine, New Haven, CT, USA; ${ }^{2}$ Faculty of Medical Sciences, The University of The West Indies Cave Hill Campus, \\ Bridgetown, Barbados; ${ }^{3}$ Unit of Public Health and Primary Care, Faculty of Medical Sciences, The University of the West Indies, St. Augustine, Trinidad \\ and Tobago; ${ }^{4}$ The University of Puerto Rico, San Juan, PR, USA; ${ }^{5}$ The University of the US Virgin Islands, Charlotte Amalie, USA.
}

BACKGROUND: Cardiovascular disease (CVD) is the leading cause of morbidity and mortality in the Caribbean region.

OBJECTIVE: This study explored the concept of a health network, relationships focused on health-related matters, and examined associations with CVD risk factors in the Eastern Caribbean.

DESIGN: The Eastern Caribbean Health Outcomes Research Network Cohort Study is an ongoing longitudinal cohort being conducted in the US Virgin Islands, Puerto Rico, Trinidad and Tobago, and Barbados.

PARTICIPANTS: Participants $(n=1989)$ were English or Spanish-speaking adults 40 years and older, who were residents of the island for at least 10 years, and who intended to live on-island for the next 5 years.

MAIN MEASURES: Logistic regression was used to examine associations between health network characteristics and CVD risk factors: physical activity, hypertension, and smoking. A baseline survey asked questions about health networks using name generator questions that assessed who participants spoke to about health matters, whose opinions on healthcare mattered, and who they would trust to make healthcare decisions on their behalf.

KEY RESULTS: Health networks were mainly comprised of family members and friends. Healthcare professionals comprised $7 \%$ of networks, mean network size was four, and $74 \%$ of health network contacts were perceived to be in "good" to "excellent" health. Persons with larger health networks had greater odds of being physically active compared with those with smaller networks $(\mathrm{OR}=1.07, \mathrm{CI}=1.01-$ $1.14)$.

CONCLUSIONS: Health networks may be useful to intervention efforts for CVD risk factor reduction. More studies are needed to examine health networks in Caribbean contexts and explore associations with other CVD risk factors.

Received May 8, 2019

Revised September 27, 2019

Accepted October 30, 2019

Published online December 10, 2019
KEY WORDS: social network; cardiovascular; hypertension; smoking; physical activity; Caribbean.

J Gen Intern Med 35(3):784-91

DOI: $10.1007 / \mathrm{s} 11606-019-05550-1$

(C) Society of General Internal Medicine 2019

\section{INTRODUCTION}

Cardiovascular disease (CVD) is a leading cause of morbidity and mortality in the Caribbean region. ${ }^{1-5}$ Lifestyle and behavioral risk factors, including physical inactivity and smoking, are major contributing factors. ${ }^{4,6}$ There has also been an increase in related clinical risk factors like diabetes and hypertension in the region. ${ }^{1,2,5,7-9}$ The epidemiologic transition in the Caribbean, accompanied by more sedentary lifestyles and calorie-dense diets, has led to increases in these clinical and lifestyle risk factors. Addressing these risk factors is therefore critical to reducing the burden associated with cardiovascular diseases in the region. ${ }^{10}$

Prior epidemiological evidence suggests that CVD risk factors are influenced by behaviors and exposures that are embedded in social networks. ${ }^{11,12}$ A social network refers to the structure of an individual's interpersonal relationships and social interactions, both in terms of quality and quantity. ${ }^{13}$ The individuals that comprise a given social network are sources of social support, resources, and information. They influence health behaviors and decisions through the social norms that exist within social networks. ${ }^{12-14}$ Network theorists have proposed two main processes through which social networks facilitate spread of health behavior: contagion and homophily. The contagion theory posits that the networks in which people are embedded influence behavior over time, while the homophily theory proposes that a person's network develops by self-selection based on similar behavioral characteristics. Through these processes, behavioral norms are spread and contribute to the development of healthy and unhealthy behaviors associated with CVD risk factors.

A large body of literature has investigated social network influences on health behaviors including smoking and alcohol 
misuse. ${ }^{13-16}$ These behaviors contribute to the development of risk factors that lead to incident cardiovascular events (e.g., stroke, heart disease, congestive heart failure). Findings have been mixed in demonstrating direct associations between social networks and incident cardiovascular events. ${ }^{11,}$ 17-19 Some studies show smaller social networks are associated with increased risk of incident stroke and heart disease, while other studies fail to demonstrate statistically significant associations or show inconsistent findings. ${ }^{11,18,19}$ Findings for obesity consistently show spread of obesity within networks, demonstrating strong evidence of social network influence. ${ }^{12}$, 20, 21 Studies have also investigated social networks in healthcare contexts and have demonstrated that social networks can influence healthcare information exchange, decision-making, and health behavior. ${ }^{2-24}$ Griffiths et al. (2012) found that healthcare-related social networks encouraged greater health information exchange among patients regarding clinical diagnosis, treatment, and experiences with providers. A similar study found that social networks influenced patients to take a more active role in their health, ${ }^{25}$ and that individuals often seek healthcare advice from other network members, ${ }^{26}$ including family contacts. ${ }^{23,27}$ This body of evidence has led to innovative uses of social networks to positively influence health behaviors and diffuse healthcare information. ${ }^{13}, 28,29$ Results from studies utilizing social network-based interventions vary in demonstrating success in positively influencing health and healthcare behaviors. Among studies with statistically significant findings, effect sizes were modest. ${ }^{14}, 29-31$ Though mixed, the body of evidence on the utility of social network phenomena in changing health behavior suggests potential and the need for further research. To date, there have been few social network studies conducted in the Caribbean. Our literature search identified two studies. One study examined the relationship between network structures and injection drug use in Puerto Rico and another examined social network relationships to understand co-management of fisheries. ${ }^{32,33}$ Few studies have examined how interpersonal relationships and social networks are tied to CVD risk factors that are prevalent and pose burden to the region.

Given the evidence on social networks and health, increasing prevalence of CVD risk factors, and paucity of evidence in the Caribbean, we leveraged data from the Eastern Caribbean Health Outcomes Research Network Cohort Study (ECS) to examine social network phenomena. The purpose of this study was to assess characteristics of networks and determine whether network characteristics are associated with risk factors that

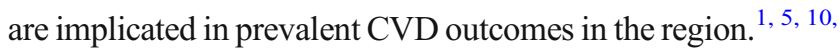
34, 35 This study expands prior work in two important ways: (1) restricting social networks to persons with whom health matters are discussed to explore the concept of a "health network," and (2) examining associations between health network characteristics and prevalent CVD risk factors not previously explored. We refer to health networks from here on, instead of social networks, which we define as relationship structures within broader social networks that are defined according to or based on health and health matters. We explored this concept across four island sites that comprise the ECS cohort.

\section{METHODS Data Source and Study Sample}

Data from the ECS were used to address the study aims. The ECS is an ongoing longitudinal cohort study conducted across four Caribbean sites: the U.S. Virgin Islands, Puerto Rico, Trinidad and Tobago, and Barbados. The study aims to identify novel risk and protective factors for non-communicable diseases, including cardiovascular disease, diabetes, and cancer, in the Eastern Caribbean region. Between 2013-2018, stratified multi-stage random sampling was used to empanel the ECHORN cohort $(N=2957)$ in Barbados, Trinidad, and Puerto Rico, and random digit sampling was used in the U.S. Virgin Islands of St. Thomas and St. Croix. Eligible participants were English or Spanish-speaking community-dwelling adults 40 years of age and older, who were residents of the island for at least 10 years, and who intended to live on-island for the next 5 years. At baseline, participants completed a survey including self-reported measures of lifestyle factors, health outcomes, medical history, and demographic characteristics. In addition, a brief health network questionnaire was administered to all participants. Participants also underwent a clinical examination during which blood pressure and anthropometric measurements, ECG, blood and urine samples, and medication information were collected. Participants with complete, self-reported baseline data and health network questions were included in the current analyses $(n=1989)$.

\section{Health Network Characteristics}

Health networks were examined from participant (referred to as "ego") self-report or an egocentric point of view. An egocentric method of examining network characteristics is one in which information is obtained from the ego's perspective about his/her health contacts (referred to as "alters"). This approach contrasts a sociocentric approach in which information is obtained from everyone in a defined group (i.e., egos and alters). An egocentric approach was used since investigators were interested in examining how personal health networks influence the "ego's" health and health behavior. A brief questionnaire was administered to egos during survey intake for the ECHORN baseline survey. Egos were asked to name and describe persons who comprised their health network. The following name generator questions were used to identify participants' health network members:

1. Name three to five people with whom you talk to about health information

2. Name three to five people whose opinions on healthcare matter to you 
3. Name three to five people you would trust to make a healthcare decision if you were unable to

For each alter, participants provided information on the age, sex, occupation, length of time they have known the alter, type of relationship, residence, and perceived health of each alter in their health network. Health network characteristics were calculated as means or proportions for inclusion in analyses. Network characteristics examined in these analyses included (1) mean age of the health network; (2) proportion of network of the same sex; (3) proportion of women; (4) proportion of network members known $\geq 20$ years; (5) mean difference in age between ego and each alter; (6) proportion of contacts perceived to be in good or excellent health; (7) proportion of contacts who live off-island; (8) proportion of contacts with strong influence or alters who were named for all three name generator questions; (9) proportion of relationship types; and (10) average network size.

\section{Covariates}

Factors known to be associated with network characteristics and cardiovascular risk factors (i.e., hypertension, physical activity, and smoking) were examined. ${ }^{12,13,21,23,36}$ Covariates included age, marital status (single, married, divorced/ separated/widowed), body mass index, educational attainment, perceived economic status, and study site. Variables were self-reported by participants except for body mass index which was calculated from weight and height collected during the clinical exam. Educational attainment was measured by asking participants to report their highest year of school completed. Responses were collapsed into four categories: (1) less than high school, (2) high school, (3) some college, and (4) college and beyond. Perceived economic status was measured using the Gallop World Poll question ${ }^{37}$ that asks participants to rank their status on a scale from 1 to 10 with 10 being the richest regarding social status. Responses were categorized as bottom $25 \%$, middle, and top $25 \%$ for inclusion in analyses.

\section{CVD Risk Factors}

Risk factors strongly associated with CVD risk were examined-smoking, physical activity, and hypertension. Smoking and physical inactivity are major modifiable lifestyles and hypertension is a leading clinical risk factor associated with CVD in the region and beyond. ${ }^{36,38-41}$ Outcomes were measured by participant self-report. Smoking was measured using questions from the Coronary Artery Risk Development in Young Adults (CARDIA) Questionnaire ${ }^{42}$ and categorized as current versus never and past smokers; physical activity was measured using the WHO Global Physical Activity Questionnaire ${ }^{43}$ and categorized as low versus medium/ high activity; and hypertension was defined by participant self-report and results of blood pressure measurements from the clinical examination. This included persons with elevated blood pressure during clinical examination without a history of hypertension. Hypertension was measured as a binary variable (yes/no) using The Seventh Report of the Joint National Committee on Prevention, Detection, Evaluation, and Treatment of High Blood Pressure (JNC-7) clinical guidelines. ${ }^{44}$ Persons with diastolic blood pressure $\geq 90$ or systolic blood pressure $\geq 140$ were categorized as having hypertension; those with diastolic blood pressure $<90$ and systolic blood pressure less than 140 were categorized as not having hypertension.

\section{Statistical Analysis}

Univariate analyses were conducted to examine frequencies and distributions of health network variables and to describe the networks of ECS participants. Bivariate analyses were conducted using $t$ tests and chi-squared tests, as appropriate, to determine variables for inclusion in multivariate models for each outcome. Multicollinearity between variables was also assessed. The proportion of same sex contacts was correlated with participant age and was therefore not included in multivariate analyses. Separate logistic regression models were performed for each outcome to examine associations with health network characteristics. All health network variables were included in descriptive analyses; however, multivariate analyses were restricted to those variables that were statistically significant in the bivariate analyses or have been found to be associated with our outcomes in prior research. ${ }^{45}$ Final analyses included data for 1989 ECS participants who had complete health network and risk factor data. Participants with missing data on key study variables $(n=986)$ were excluded from the current analyses.

The ECS study was approved by the Yale University $\mathrm{Hu}-$ man Subjects Investigation Committee, the Institutional Review Boards of the University of Puerto Rico Medical Sciences Campus, the University of the Virgin Islands, the University of the West Indies Cave Hill Campus, and the Ministry of Health of Trinidad and Tobago. The current analysis was approved by the Data Access and Scientific Review Committee of the ECS.

\section{RESULTS}

\section{Participant Characteristics}

Most participants were between the ages of 50 and 69 years and $68 \%$ were women (Table 1). Thirty-five percent of participants had less than a high school education and $51 \%$ perceived themselves as having middle economic status. Forty-one percent of participants reported being married or single.

Table 1 also describes characteristics of participants' health networks. Health networks mainly comprised family members (49\%) followed by friend (23\%), and partner/spouse (11\%). Seven percent of health network contacts were healthcare professionals, most of whom were physicians and the 
Table 1 ECHORN Participant Demographics

\begin{tabular}{|c|c|c|}
\hline \multirow{2}{*}{$\begin{array}{l}\text { Participant characteristics } \\
\text { Age - mean, SD }\end{array}$} & \multicolumn{2}{|c|}{$\begin{array}{l}\text { Total }(n= \\
1989)\end{array}$} \\
\hline & 57.1 & 10.4 \\
\hline \multicolumn{3}{|l|}{$\operatorname{Sex}(n, \%)$} \\
\hline Female & 1342 & 67.5 \\
\hline \multicolumn{3}{|l|}{ Marital status $(n, \%)$} \\
\hline Single & 819 & 41.2 \\
\hline Married & 809 & 40.7 \\
\hline Divorced/separated & 213 & 10.7 \\
\hline Widowed & 148 & 7.4 \\
\hline \multicolumn{3}{|l|}{ Education $(n, \%)$} \\
\hline Less than high school & 696 & 35.0 \\
\hline High school & 491 & 24.7 \\
\hline Some college & 437 & 22.0 \\
\hline College+ & 365 & 18.4 \\
\hline \multicolumn{3}{|l|}{ Current perceived economic status $(n, \%)$} \\
\hline Bottom $25 \%$ & 487 & 24.5 \\
\hline Middle & 1023 & 51.4 \\
\hline Top $25 \%$ & 479 & 24.1 \\
\hline \multicolumn{3}{|l|}{ Health network characteristics } \\
\hline Number of contacts - mean, SD & 4.1 & 1.9 \\
\hline Mean age of contacts - mean, SD & 51.1 & 9.6 \\
\hline Difference in age with contacts - mean, SD & 6.0 & 11.8 \\
\hline Percent same sex - mean, SD & 59.6 & 29.0 \\
\hline $\begin{array}{l}\text { Percent of contacts with good to excellent health - } \\
\text { mean. SD }\end{array}$ & 73.7 & 29.9 \\
\hline \multicolumn{3}{|l|}{ Number of contacts who live off-island - $(n, \%)$} \\
\hline 0 & 1556 & 78.2 \\
\hline $1+$ & 433 & 21.8 \\
\hline Percent of contacts with strong influence - mean, SD & 32.7 & 37.1 \\
\hline Percent of contacts known over 20 years - mean, SD & 72.4 & 27.9 \\
\hline \multicolumn{3}{|l|}{ Percent of contacts -relationship type - mean, SD } \\
\hline Family & 48.9 & 29.8 \\
\hline Friend & 23.0 & 26.8 \\
\hline Partner & 11.3 & 17.4 \\
\hline Health provider & 6.7 & 15.1 \\
\hline Associate & 3.7 & 11.8 \\
\hline Other & 6.3 & 17.5 \\
\hline
\end{tabular}

remainder of networks comprised "associates" and "others." Sixty percent of egos' health contacts were women and the mean age of contacts was 51 years \pm 10 . Health networks comprised $4 \pm 2$ alters on average. Seventy-four percent of named health contacts were perceived to be in good to excellent health. Twenty-two percent of health contacts named by participants did not reside in the same island site. Most health contacts were known by participants for 20 or more years on average.

Table 2 presents frequencies for hypertension, physical inactivity, and smoking. Fifty-nine percent of participants reported having hypertension, $45 \%$ reported not engaging in

Table 2 Prevalence of Cardiovascular Risk Factors in the ECHORN Cohort

\begin{tabular}{lll}
\hline \hline Outcome & $\boldsymbol{n}$ & \% \\
\hline Hypertensive & 823 & \\
$\quad$ No & 1166 & 41.4 \\
$\quad$ Yes & 1848 & 58.6 \\
Current smoker & 141 & 92.9 \\
$\quad$ No & & 7.1 \\
$\quad$ Yes & 893 & 44.9 \\
Moderate to high physical activity & & 55.1 \\
No & 1096 & \\
Yes & &
\end{tabular}

moderate to high physical activity, and $7 \%$ of participants reported being smokers.

\section{Bivariate and Multivariate Results}

Bivariate results (Table 3) showed that health network size, mean age of health contacts, and mean difference in age with health contacts was significantly associated with outcomes. Results for age, marital status, and educational attainment showed statistically significant associations with outcomes. After adjustment for demographic covariates (Table 4), health network characteristics were no longer associated with hypertension and smoking outcomes. The association between health network size and physical activity remained after adjustment (OR $=1.07$, CI 1.01-1.14). The inclusion of each additional contact in a health network is associated with $10 \%$ greater odds of being physically active.

Other health network characteristics were not significantly associated with physical activity. Age, gender, educational attainment, and marital status were associated with outcomes (data not shown). Age was positively associated with hypertension for persons between 50 and 59 years $(\mathrm{OR}=1.65, \mathrm{CI}$ $0.95-2.86)$; men had greater odds of smoking $(\mathrm{OR}=2.54$, CI $1.80-3.58)$ and being physically active ( $\mathrm{OR}=1.82$, CI 1.50 2.21) compared with women, and persons who were widowed had increased odds of hypertension $(\mathrm{OR}=2.94$, CI 1.94-4.46) and lower odds of physical activity $(\mathrm{OR}=0.48$, CI $0.33-0.68)$ compared with those who were single. Persons with college education had decreased odds of hypertension $(\mathrm{OR}=0.55$, CI $0.42-0.71)$ and increased odds of physical activity $(\mathrm{OR}=0.76$, CI 0.59-0.98) compared with those with less than a high school education.

\section{DISCUSSION}

Our findings demonstrate the potential merit of "health networks" based on the theory that individuals have networks embedded in larger networks that serve different purposes and have varied levels of influence regarding health. ${ }^{46,} 47$ This study examined associations between health network characteristics and CVD risk factors in Caribbean contexts, which has not previously been done to our knowledge. Our study findings demonstrated a weak yet statistically significant association between network size and physical activity. Specifically, persons with larger health networks had an increased odds of being physically active. We compared our results to findings from studies of social networks in the absence of a body of literature on health networks. Consistency with prior literature focused on network size and health-related outcomes was mixed. Baek et al. (2016) found that having a large network was associated with decreased odds of hypertension among older Korean men. ${ }^{48}$ More recent evidence from Marquez et al. (2018) showed larger networks were associated with increased moderate to vigorous exercise. ${ }^{49}$ While mechanisms that explain this association are still under-theorized, 
Table 3 Unadjusted Odds of Being Hypertensive, Current Smoker, and Physically Active by Characteristics

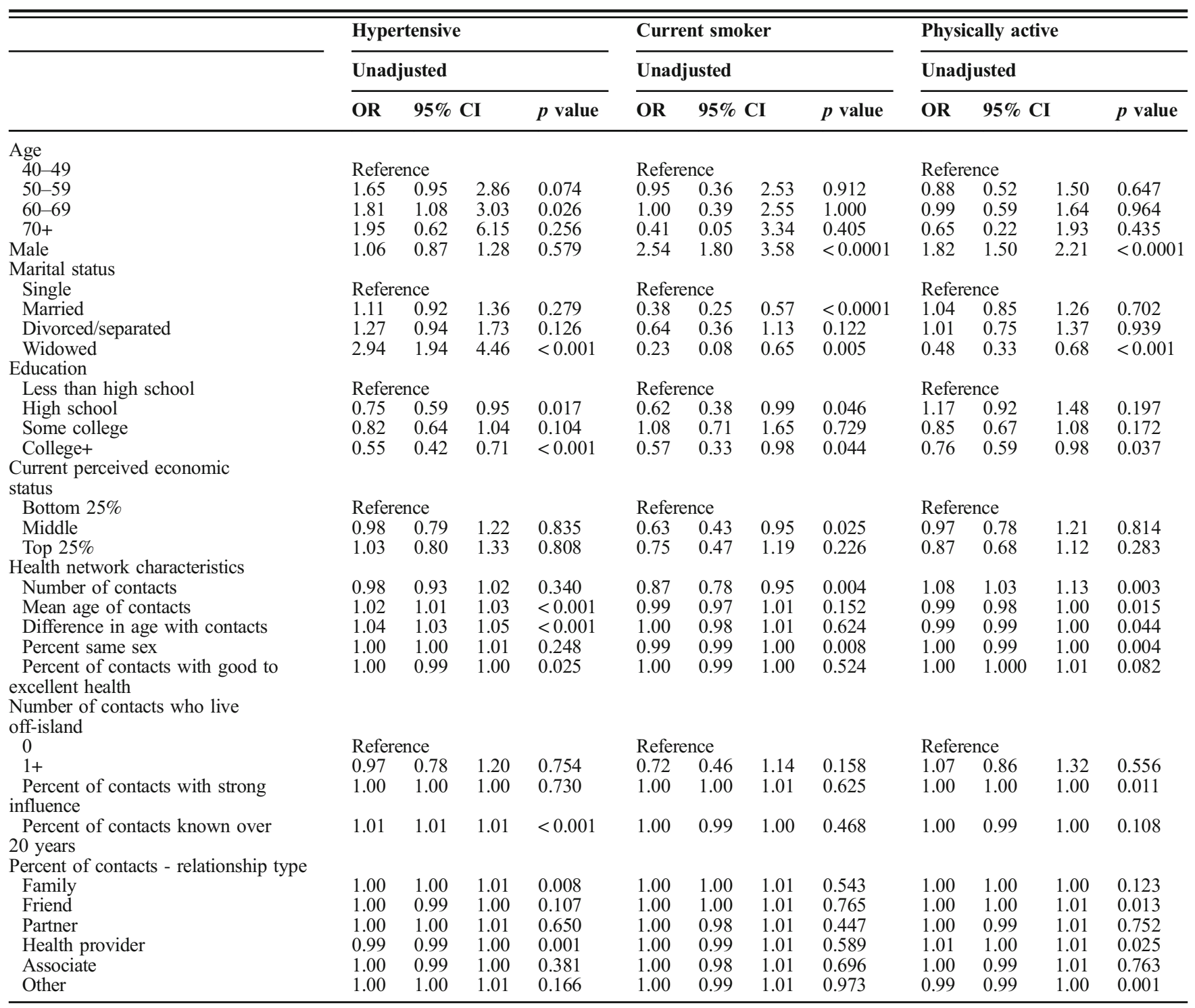

some evidence suggests that larger networks provide greater social support by increasing opportunities and tangible/ instrumental support that promote physical activity. ${ }^{49-51}$ Larger network sizes have also been shown to facilitate mirroring or aspirations related to body size and exercise. ${ }^{51}$ Larger networks provide emotional support that is associated with health screening and diagnosis. ${ }^{23,} 52$ Contrasting our study findings, other studies show that larger social networks do not precipitate health-promoting behavior. Studies show that egos who have a high proportion of network members who smoke are more likely themselves to smoke. ${ }^{21,} 53$ Similarly, egos who have a larger number of physically active or obese network members are more likely to be active or obese themselves. ${ }^{12,} 54,55$

To date, few studies have examined network phenomenon in Caribbean contexts. ${ }^{32,33}$ Our findings showed that health networks were primarily comprised of family members and not physicians or health professionals as hypothesized. This illustrated the more prominent role that family contacts play in health networks compared with healthcare providers. This is the first known study to examine network phenomena and health in the region.

We acknowledge limitations in conducting our study. First, our egocentric approach to examine health network characteristics precludes the ability to verify egos' perceptions with their named health contacts (i.e., alters). Therefore, it is possible that egos' perceptions of health are inaccurate. We hypothesize that the possibility of inaccurate perceptions is minimal given small geographic context of research sites, high proportion of family in networks, and length of time that egos reported knowing contacts. Other limitations include the inability to examine or adjust for frequency of contact with 
Table 4 Adjusted* Odds of Being Hypertensive, Current Smoker, and Physically Active by Social Network Characteristics

\begin{tabular}{|c|c|c|c|c|c|c|c|c|c|c|c|c|}
\hline & \multicolumn{4}{|c|}{ Hypertensive } & \multicolumn{4}{|c|}{ Current smoker } & \multicolumn{4}{|c|}{ Physically active } \\
\hline & \multicolumn{4}{|c|}{ Adjusted } & \multicolumn{4}{|c|}{ Adjusted } & \multicolumn{4}{|c|}{ Adjusted } \\
\hline & OR & $95 \%$ & CI & $\begin{array}{l}p \\
\text { value }\end{array}$ & OR & $95 \%$ & CI & $\begin{array}{l}p \\
\text { value }\end{array}$ & OR & $95 \%$ & CI & $\begin{array}{l}p \\
\text { value }\end{array}$ \\
\hline \multicolumn{13}{|l|}{ Health network characteristics } \\
\hline Number of contacts & 0.98 & 0.93 & 1.05 & 0.618 & 0.88 & 0.78 & 1.00 & 0.045 & 1.07 & 1.01 & 1.14 & 0.026 \\
\hline Mean age of contacts & 1.00 & 0.99 & 1.01 & 0.464 & 0.99 & 0.97 & 1.01 & 0.211 & 0.99 & 0.98 & 1.00 & 0.232 \\
\hline Percent same sex & 1.00 & 1.00 & 1.00 & 0.994 & 1.00 & 0.99 & 1.01 & 0.525 & 1.00 & 1.00 & 1.00 & 0.785 \\
\hline $\begin{array}{l}\text { Percent of contacts with good to excellent } \\
\text { health }\end{array}$ & 1.00 & 0.99 & 1.00 & 0.010 & 1.00 & 0.99 & 1.00 & 0.356 & 1.00 & 1.00 & 1.01 & 0.064 \\
\hline \multicolumn{13}{|l|}{ Number of contacts who live off-island } \\
\hline 0 & \multicolumn{4}{|c|}{ Reference } & \multicolumn{4}{|c|}{ Reference } & \multicolumn{4}{|c|}{ Reference } \\
\hline $1+$ & 0.90 & 0.71 & 1.16 & 0.418 & 0.88 & 0.54 & 1.43 & 0.599 & 1.04 & 0.82 & 1.31 & 0.766 \\
\hline Percent of contacts with strong influence & 1.00 & 1.00 & 1.00 & 0.978 & 1.00 & 0.99 & 1.00 & 0.372 & 1.00 & 1.00 & 1.00 & 0.139 \\
\hline Percent of contacts known over 20 years & 1.00 & 1.00 & 1.01 & 0.349 & 1.00 & 0.99 & 1.01 & 0.863 & 1.00 & 1.00 & 1.00 & 0.771 \\
\hline \multicolumn{13}{|l|}{ Percent of contacts -relationship type } \\
\hline Family & 1.00 & 0.99 & 1.01 & 0.562 & 1.01 & 0.99 & 1.02 & 0.577 & 1.00 & 1.00 & 1.01 & 0.473 \\
\hline Friend & 1.00 & 0.99 & 1.01 & 0.944 & 1.00 & 0.99 & 1.02 & 0.646 & 1.01 & 1.00 & 1.01 & 0.204 \\
\hline Partner & 1.00 & 0.99 & 1.01 & 0.565 & 1.00 & 0.98 & 1.02 & 0.940 & 1.01 & 1.00 & 1.02 & 0.224 \\
\hline Health provider & 1.00 & 0.99 & 1.02 & 0.431 & 1.00 & 0.98 & 1.02 & 0.844 & 1.00 & 0.99 & 1.01 & 0.957 \\
\hline Associate & \multicolumn{4}{|c|}{ Reference } & \multicolumn{4}{|c|}{ Reference } & \multicolumn{4}{|c|}{ Reference } \\
\hline Other & 1.00 & 0.99 & 1.01 & 0.407 & 1.01 & 0.99 & 1.02 & 0.593 & 1.00 & 0.99 & 1.01 & 0.538 \\
\hline
\end{tabular}

*adjusted for age, gender, marital status, education, and current perceived economic status

health network members. It is possible that the lower prevalence of smoking observed in our study compared with others in the region may reflect underreporting. However, we believe that our estimate is likely explained by differences in the age of our study population compared with other studies. Most in-region estimates are based on younger study populations (e.g., 13 and older) ${ }^{56,57}$; therefore, the lower smoking prevalence we observed may truly reflect prevalence among those 40 and older. Further, our estimate (7.1) is similar to estimates observed in the 2015 study that included persons 35 and older. ${ }^{58}$ Our measure of physical activity may be subject to biases shown to be associated with selfreported physical activity. ${ }^{59,}{ }^{60}$ Future work will seek to examine associations using objective measures of physical activity. Finally, it is possible that name generation questions performed differentially across participant demographic characteristics. This may have resulted in differential interpretation and responses. However, this is unlikely, given the variation in the health contacts that were named. Further, name generator questions are designed in a manner to reduce the potential for participants to be influenced.

Though many health network characteristics (except network size) were not significantly associated with health outcomes examined in this study, evidence suggests there is promise in leveraging networks to modify health behaviors. Findings on the benefit of network approaches for health behavior intervention are mixed, however there is some evidence to suggest utility of network approaches to increase healthful behaviors. ${ }^{21,} 23,49,61-63$ Given the resource limited contexts, health network ties could serve as an important source of health information and resources. ${ }^{64}$ The identification of health network approaches to promote health in the region could have immeasurable benefit. Our future work will explore other health behaviors and outcomes in Caribbean contexts to determine how health networks can be leveraged to promote healthy behaviors and identify health behaviors that are most amenable to network approaches.

Corresponding Author: Carol R. Oladele, $\mathrm{PhD}, \mathrm{MPH}$; Yale University School of Medicine, New Haven, CT, USA (e-mail: carol.oladele@yale. edu).

Funding Information This research was supported by the Yale CTSA grant UL1TROOO142 from the National Center for Advancing Translational Science (NCATS), Yale School of Medicine, and the National Institute on Minority Health and Health Disparities through the Yale Transdisciplinary Collaborative Center for Health Disparities Research focused on Precision Medicine (Yale-TCC)-U54MD010711.

Data Availability The datasets analyzed for the current study are available from the corresponding author on reasonable request.

\section{Compliance with Ethical Standards:}

The current analysis was approved by the Data Access and Scientific Review Committee of the ECS.

Conflict of Interest: The authors declare that they do not have a conflict of interest.

\section{REFERENCES}

1. Ayinde H, Gillum RF. Cardiovascular disease mortality in Sub-Saharan Africa and the Caribbean. Ethn Dis 2014;24(4):495-501.

2. Ferguson TS, Francis DK, Tulloch-Reid MK, Younger NOM, McFarlane SR, Wilks RJ. An update on the burden of cardiovascular disease risk factors in Jamaica: findings from the Jamaica Health and Lifestyle Survey 2007-2008. West Indian Med J 2011;60.

3. Ferguson TS, Tulloch-Reid MK, Wilks RJ. The epidemiology of diabetes mellitus in Jamaica and the Caribbean: a historical review. West Indian Med J 2010;59(3):259-64.

4. Tulloch-Reid MK, Younger NO, Ferguson TS, Francis DK, Abdulkadri AO, Gordon-Strachan GM, et al. Excess cardiovascular risk burden in Jamaican women does not influence predicted 10-year CVD risk profiles of Jamaica adults: an analysis of the 2007/08 Jamaica Health and Lifestyle Survey. PLoS One 2013;8(6):e66625. 
5. Francis DK, Bennett NR, Ferguson TS, Hennis AJ, Wilks RJ, Harris EN, et al. Disparities in cardiovascular disease among Caribbean populations: a systematic literature review. BMC Publ health. 2015;15(1).

6. Ferguson TS, Younger NOM, Tulloch-Reid MK, Wright MBL, Ward EM Ashley DE, et al. Prevalence of prehypertension and its relationship to risk factors for cardiovascular disease in Jamaica: analysis from a crosssectional survey. BMC Cardiovasc Disord. 2008;8:20.

7. Howitt C, Hambleton IR, Rose AMC, Hennis A, Samuels TA, George KS, et al. Social distribution of diabetes, hypertension and related risk factors in Barbados: a cross-sectional study. BMJ Open. 2015;5(12):e008869-e.

8. Foster C, Rotimi C, Fraser H, Sundarum C, Liao Y, Gibson E, et al. Hypertension, diabetes, and obesity in Barbados: findings from a recent population-based survey. Ethn Dis 1993;3(4):404-12.

9. Hennis A, Nemesure B, Leske MC, Wu S-Y, Li X, for The Barbados Eye Studies G, et al. Diabetes in a Caribbean population: epidemiological profile and implications. Int J Epidemiol 2002;31(1):234-9.

10. Block RC, Dozier AM, Hazel-Fernandez L, Guido JJ, Pearson TA. An epidemiologic transition of cardiovascular disease risk in Carriacou and Petite Martinique, Grenada: the Grenada Heart Project, 2005-2007. Prev Chronic Dis 2012;9:E90.

11. Nagayoshi M, Everson-Rose SA, Iso H, Mosley TH, Jr., Rose KM Lutsey PL. Social network, social support, and risk of incident stroke: Atherosclerosis Risk in Communities study. Stroke. 2014;45(10):286873.

12. Christakis NA, Fowler JH. The spread of obesity in a large social network over 32 years. N Engl J Med 2007;357(4):370-9.

13. Smith KP, Christakis NA. Social networks and health. Annu Rev Sociol 2008;34(1):405-29.

14. Latkin C, Donnell D, Liu T-Y, Davey-Rothwell M, Celentano D Metzger D. The dynamic relationship between social norms and behaviors: the results of an HIV prevention network intervention for injection drug users. Addiction. 2013;108(5):934-43.

15. Latkin C, Donnell D, Celentano DD, Aramrattna A, Liu T-Y, Vongchak T, et al. Relationships between social norms, social network characteristics, and HIV risk behaviors in Thailand and the U.S. Health Psychol 2009;28(3):323-9.

16. Lau-Barraco C, Collins RL. Social networks and alcohol use among nonstudent emerging adults: a preliminary study. Addict Behav 2011;36(0):47-54

17. Kawachi I, Colditz GA, Ascherio A, Rimm EB, Giovannucci E Stampfer MJ, et al. A prospective study of social networks in relation to total mortality and cardiovascular disease in men in the USA. J Epidemiol Commun Health 1996;50(3):245-51.

18. Rutledge TP, Linke SEBA, Olson MBMS, Francis JP, Johnson BDP, Bittner VMDM, et al. Social networks and incident stroke among women with suspected myocardial ischemia. Psychosom Med 2008;70(3):282-7.

19. Vogt TM, Mullooly JP, Ernst D, Pope CR, Hollis JF. Social networks as predictors of ischemic heart disease, cancer, stroke and hypertension: incidence, survival and mortality. J Clin Epidemiol 1992;45(6):659-66.

20. Nam S, Redeker N, Whittemore R. Social networks and future direction for obesity research: a scoping review. Nurs Outlook 2015;63(3):299-317.

21. Roberts ME, Nargiso JE, Gaitonde LB, Stanton CA, Colby SM Adolescent social networks: general and smoking-specific characteristics associated with smoking. J Stud Alcohol Drugs 2015;76(2):247-55.

22. Griffiths F, Cave J, Boardman F, Ren J, Pawlikowska T, Ball R, et al. Social networks - the future for health care delivery. Soc Sci Med 2012;75(12):2233-41.

23. Marquez B, Elder JP, Arredondo EM, Madanat H, Ji M, Ayala GX. Social network characteristics associated with health promoting behaviors among Latinos. Health Psychol 2014;33(6):544-53.

24. Heijmans $\mathbf{N}$, van Lieshout $\mathbf{J}$, Wensing $\mathbf{M}$. Social network composition of vascular patients and its associations with health behavior and clinical risk factors. PLoS One 2017;12(9):e0185341.

25. Gage EA. Social networks of experientially similar others: formation, activation, and consequences of network ties on the health care experience. Soc Sci Med (1982). 2013;95:43-51.

26. Cook-Craig P, Ely G, Flaherty C, Dignan M, White CR. Seeking health advice from social networks in low-income urban neighborhoods. Am J Health Behav 2012;36(6):723-35.

27. Sriram U, Morgan EH, Graham ML, Folta SC, Seguin RA. Support and sabotage: a qualitative study of social influences on health behaviors among rural adults. J Rural Health 2018;34(1):88-97.

28. Laranjo L, Arguel A, Neves AL, Gallagher AM, Kaplan R, Mortimer N, et al. The influence of social networking sites on health behavior change: a systematic review and meta-analysis. J Am Med Inform Assoc 2015;22(1):243-56

29. Maher CA, Lewis LK, Ferrar K, Marshall S, De Bourdeaudhuij I Vandelanotte C. Are health behavior change interventions that use online social networks effective? A systematic review. J Med Internet Res 2014;16(2):e40.

30. Latkin CA, Knowlton AR. Social network assessments and interventions for health behavior change: a critical review. Behav Med 2015;41(3):90-7.

31. van Woudenberg TJ, Bevelander KE, Burk WJ, Smit CR, Buijs L, Buijzen M. A randomized controlled trial testing a social network intervention to promote physical activity among adolescents. BMC Publ Health 2018; 18(1):542.

32. Alexander SM, Armitage D, Charles A. Social networks and transitions to co-management in Jamaican marine reserves and small-scale fisheries. Glob Environ Chang 2015;35:213-25.

33. Coronado-Garcia M, Thrash CR, Welch-Lazoritz M, Gauthier R, Reyes JC, Khan B, et al. Using network sampling and recruitment data to understand social structures related to community health in a population of people who inject drugs in rural Puerto Rico. P R Health Sci J 2017;36(2):77-83.

34. Colgrove P, Connell KL, Lackland DT, Ordunez P, DiPette DJ. Controlling hypertension and reducing its associated morbidity and mortality in the Caribbean: implications of race and ethnicity. J Clin Hyper 2017;19(10): 1010-4.

35. Figueroa J, Harris M, Duncan J, Tulloch-Reid M. Hyper Control 2017;66(1): 1-3.

36. Diaz KM, Booth JN, 3rd, Calhoun DA, Irvin MR, Howard G, Safford MM, et al. Healthy lifestyle factors and risk of cardiovascular events and mortality in treatment-resistant hypertension: the Reasons for Geographic and Racial Differences in Stroke study. Hypertension. 2014;64(3):46571.

37. Deaton A. Income, health, and well-being around the world: evidence from the Gallup World Poll. J Econ Perspect 2008;22(2):53-72.

38. Doulougou B, Gomez F, Alvarado B, Guerra RO, Ylli A, Guralnik J et al. Factors associated with hypertension prevalence, awareness, treatment and control among participants in the International Mobility in Aging Study (IMIAS). J Hum Hypertens 2016;30(2):112-9.

39. Diaz KM, Shimbo D. Physical activity and the prevention of hypertension. Curr Hypertens Rep 2013;15(6):659-68.

40. Burke GM, Genuardi M, Shappell H, D'Agostino RB, Sr., Magnani JW. Temporal associations between smoking and cardiovascular disease, 1971 to 2006 (from the Framingham Heart Study). Am J Cardiol 2017;120(10):1787-91.

41. Stevens SL, Wood S, Koshiaris C, Law $\mathbf{K}$, Glasziou P, Stevens RJ, et al. Blood pressure variability and cardiovascular disease: systematic review and meta-analysis. BMJ. 2016;354:i4098.

42. Friedman GD, Cutter GR, Donahue RP, Hughes GH, Hulley SB, Jacobs DR, et al. Cardia: study design, recruitment, and some characteristics of the examined subjects. J Clin Epidemiol 1988;41(11):1105-16.

43. Armstrong T, Bull F. Development of the World Health Organization Global Physical Activity Questionnaire (GPAQ). J Publ Health 2006;14(2):66-70.

44. Chobanian AV, Bakris GL, Black HR, Cushman WC, Green LA, Izzo JL. The seventh report of the Joint National Committee on Prevention, detection, evaluation, and treatment of high blood pressure: the JNC 7 report. JAMA 2003;289.

45. Welin L, Larsson B, Svärdsudd $\mathbf{K}$, Tibblin B, Tibblin G. Social network and activities in relation to mortality from cardiovascular diseases, cancer and other causes: a 12 year follow up of the study of men born in 1913 and 1923. J Epidemiol Commun Health 1992;46(2):127-32.

46. Christakis NA, Fowler JH. Social contagion theory: examining dynamic social networks and human behavior. Stat Med 2013;32(4):556-77.

47. Berkman LF, Glass T, Brissette I, Seeman TE. From social integration to health: Durkheim in the new millennium from Berkman, L.F., \& Glass, T. Social integration, social networks, social support and health. In L. F. Berkman \& I. Kawachi, Social Epidemiology. New York: Oxford University Press; and Brissette, I., Cohen S., Seeman, T. Measuring social integration and social networks. In S. Cohen, L. Underwood \& B. Gottlieb, Social Support Measurements and Intervention. New York: Oxford University Press. Social science \& medicine. 2000;51(6):843-57.

48. Baek J, Hur NW, Kim HC, Youm Y. Sex-specific effects of social networks on the prevalence, awareness, and control of hypertension among older Korean adults. J Geriatr Cardiol 2016;13(7):580-6. 
49. Marquez B, Norman G, Fowler J, Gans K, Marcus B. Egocentric networks and physical activity outcomes in Latinas. PLoS One 2018;13(6):e0199139.

50. Marquez B, Dunsiger SI, Pekmezi D, Larsen BA, Marcus BH. Social support and physical activity change in Latinas: results from the Seamos Saludables trial. Health Psychol 2016;35(12):1392-401.

51. Powell K, Wilcox J, Clonan A, Bissell P, Preston L, Peacock M, et al. The role of social networks in the development of overweight and obesity among adults: a scoping review. BMC Public Health 2015;15:996.

52. Mbah O, Ford JG, Qiu M, Wenzel J, Bone L, Bowie J, et al. Mobilizing social support networks to improve cancer screening: the $\mathrm{COACH}$ randomized controlled trial study design. BMC Cancer 2015;15:907.

53. Blok DJ, de Vlas SJ, van Empelen P, van Lenthe FJ. The role of smoking in social networks on smoking cessation and relapse among adults: a longitudinal study. Prev Med 2017;99:105-10.

54. Kennedy-Hendricks A, Schwartz H, Thornton RJ, Griffin BA, Green HD, Jr., Kennedy DP, et al. Intergenerational social networks and health behaviors among children living in public housing. Am J Public Health 2015;105(11):2291-7.

55. Sawka KJ, McCormack GR, Nettel-Aguirre A, Blackstaffe A, Perry R, Hawe P. Associations between aspects of friendship networks, physical activity, and sedentary behaviour among adolescents. J Obes 2014;2014:632689.

56. Hambleton IR, Jeyaseelan SM, Howitt C, Hennis AJ. Monitoring Caribbean tobacco use: baseline adolescent smoking prevalence and regional disparities. Salud Publica Mex. 2017;59(Suppl 1):12-21.

57. The Global Youth Tobacco Survey Collaborative Group. Tobacco use among youth: a cross country comparison. Tob Control 2002;11(3):25270 .
58. Sreeramareddy CT, Pradhan PM. Prevalence and social determinants of smoking in 15 countries from North Africa, Central and Western Asia, Latin America and Caribbean: secondary data analyses of demographic and health surveys. PLoS One 2015;10(7):e0130104.

59. Limb ES, Ahmad S, Cook DG, Kerry SM, Ekelund U, Whincup PH, et al. Measuring change in trials of physical activity interventions: a comparison of self-report questionnaire and accelerometry within the PACE-UP trial. Int J Behav Nutr Phys Act 2019;16(1):10.

60. Kowalski K, Rhodes R, Naylor PJ, Tuokko H, MacDonald S. Direct and indirect measurement of physical activity in older adults: a systematic review of the literature. Int $J$ Behav Nutr Phys Act 2012;9:148.

61. Forthofer M, Wilcox S, Kinnard D, Hutto B, Sharpe PA. Sumter county on the move! Evaluation of a walking group intervention to promote physical activity within existing social networks.16(1):22.

62. Harmon BE, Forthofer M, Bantum EO, Nigg CR. Perceived influence and college students' diet and physical activity behaviors: an examination of ego-centric social networks. BMC Public Health 2016;16:473.

63. Gudzune KA, Peyton J, Pollack CE, Young JH, Levine DM, Latkin CA, et al. Perceived diet and exercise behaviors among social network members with personal lifestyle habits of public housing residents. Health Educ Behav 2018;45(5):808-16.

64. Kelly L, Patel SA, Narayan KMV, Prabhakaran D, Cunningham SA. Measuring social networks for medical research in lower-income settings. PLoS One. 2014;9(8):e105161-e.

Publisher's Note Springer Nature remains neutral with regard to jurisdictional claims in published maps and institutional affiliations. 